\title{
Diffusion Analysis and Modeling of Potassium Sorbate in Gelatin Based Antimicrobial Film
}

\author{
Hui Wang, Jieyu He, Hongyuan Sun \\ Department of Food Science and Technology, Hainan Tropic Ocean University, Sanya, China \\ Email: hwan072@163.com
}

Received 4 May 2016; accepted 21 July 2016; published 25 July 2016

\begin{abstract}
The diffusion of potassium sorbate incorporated into gelatin based antimicrobial film was measured. Fick's second law was applied to investigate the mechanism of potassium sorbate released from the films. The mathematical model was established. The result showed that the diffusion coefficient $D$ increased with the increase of potassium sorbate concentration. The effects of temperature $5^{\circ} \mathrm{C}, 25^{\circ} \mathrm{C}$ and $35^{\circ} \mathrm{C}$ on diffusion were investigated. The mechanisms of potassium sorbate diffusion through gelatin films were mainly Fickian and determined by the power law model $M_{t} / M_{\infty}=k \times t^{n}$. A decrease in temperature from $35^{\circ} \mathrm{C}$ to $5^{\circ} \mathrm{C}$ resulted in a reduction of diffusion coefficients from $5.20 \times 10^{-12}$ to $1.36 \times 10^{-12} \mathrm{~m}^{2} / \mathrm{s}$. The diffusion coefficient of potassium sorbate is influenced by receiving solution $\mathrm{pH}$ values.
\end{abstract}

\section{Keywords}

Potassium Sorbate, Gelatin, Diffusivity, Fick's Mathematical Model

\section{Introduction}

Antimicrobial packaging protects the product from the external environment and microbial contamination, conferring numerous advantages on human health. Interest in biopolymers as packaging materials has considerably increased recently. Active packaging can be defined as a type of packaging that changes the condition of the packaged food to extend its shelf-life or improve its safety or sensory properties [1]. To control undesirable development of microorganisms at the surface of foods, active packaging materials containing antimicrobial components might be used. These materials contain within their mass or on their surface a preservative which can migrate partly or completely into the food and exercise its preservative action there [2]-[4]. Gelatin is one of the versatile biomaterials known for the excellent film forming ability. Gelatin-based film used for coating or packaging could maintain the quality of foods during storage, due to its barrier to oxygen, light and prevention of dehydration and lipid oxidation [5] [6].

Sorbic acid and its more water soluble salts are widely used as preservatives in various food products, such as cheeses and beverages. They inhibit or delay the growth of numerous microorganisms, including yeasts, molds, 
and selective bacteria with effective concentrations in the range of $0.05-0.30 \mathrm{~g} / 100 \mathrm{~mL}$ [7]. Gelatin film containing potassium sorbate has great possibility to extend the shelf-life or increase the safety of foods when it is used as packaging or coating material. Since the activity of antimicrobial films is based on the diffusion of antimicrobial entities, knowledge of diffusivity of these entities is the most important factor in developing an antimicrobial food packaging system. The diffusivities of potassium sorbate in various biopolymer films have been determined [8]-[10]. M. Ozdemir studied the diffusion mechanism of potassium sorbate in the edible whey protein isolated membrane, and the diffusion index was between 0.55 and 0.86 and the diffusion model was irregular non fick diffusion [11]. Choi reported the effect of solution $\mathrm{pH}$ and temperature of carrageenan on diffusivity of potassium sorbate in carrageenan antibacterial film. The measured range of solution $\mathrm{pH}$ had no obvious effect on diffusivity of potassium sorbate. The diffusion coefficients decreased from $4.23 \times 10^{-13} \mathrm{~m}^{2} / \mathrm{s}$ to $1.292 \times 10^{-13}$ $\mathrm{m}^{2} / \mathrm{s}$ in $\mathrm{pH} 5.2$ when the temperature dropped from $40^{\circ} \mathrm{C}$ to $5^{\circ} \mathrm{C}$ [7]. However, there are few studies of potassium sorbate from gelatin film.

The objectives of this study were to determine the diffusivity of potassium sorbate incorporated in gelatin film and investigate the effects of $\mathrm{pH}$ and temperature on this diffusivity.

\section{Materials and Methods}

\subsection{Preparation of Antimicrobial Film}

Type B gelatin (225 Bloom, Sigma Chemical Company) was extracted from bovine skin. The gelatin solution was prepared by dissolving $20 \mathrm{~g}$ of gelatin in $100 \mathrm{~mL}$ of deionized water at $70^{\circ} \mathrm{C}$ in water bath. After dissolving the solution completely, $20 \%$ (g/g of gelatin) of glycerin was added as a plasticizer and stirred for $30 \mathrm{~min}$. For the preparation of antimicrobial film, $0.2 \%, 0.5 \%$ and $1.0 \%$ potassium sorbate (g/g of gelatin) was added with glycerin. These final gelatin solutions were poured onto a Teflon coated glass plate measuring $27 \times 27 \mathrm{~cm}$. The plates were dried at $25^{\circ} \mathrm{C}$ for $48 \mathrm{~h}$, and then they were carefully removed from the glass plate. The prepared films were conditioned at $25^{\circ} \mathrm{C}$ and $50 \% \mathrm{RH}$ in a controlled environmental chamber for $48 \mathrm{~h}$ before testing. Film thickness was measured using a hand-held micrometer and was expressed as an average of 9 readings for each sample, 1 at the center and 8 around the perimeter.

\subsection{Diffusion Experiment}

The diffusion experiments of potassium sorbate from gelatin films were conducted at 3 different $\mathrm{pH}$ levels (3.5, 5.0, and 6.8). Five grams of each sample were immersed in water in conical flask, which were shaken at 150 $\mathrm{rpm}$ by means of an orbital shaker at $25^{\circ} \mathrm{C}$. During the release experiments, samples of water were drawn from the beaker at certain times, and using a UV spectrophotometer at $254 \mathrm{~nm}$ to measure the amount of released potassium sorbate. The diffusion experiments of $0.5 \%$ potassium sorbate from film were conducted at temperatures $\left(5^{\circ} \mathrm{C}, 25^{\circ} \mathrm{C}\right.$ and $\left.35^{\circ} \mathrm{C}\right)$.

\subsection{Diffusion Mathematical Model}

The diffusivity of potassium sorbate from the film into water was determined by Fick's second law, as follows [12]:

$$
\frac{\partial C}{\partial t}=D(t) \frac{\partial^{2} C}{\partial x^{2}},
$$

where $C$ is the concentration of potassium sorbate, $\mathrm{D}$ is the diffusivity, $\mathrm{x}$ is the space coordinate in the direction of transport; and $t$ is time.

For a film of thickness $l(0<x \leq l)$, the following assumptions were made: initially, the distribution of potassium sorbate in the films was uniform and the concentration of potassium sorbate in water and on the film boundaries ( $x=0$ and 1) was zero. Under the previous assumptions, a classical solution for a plane sheet of thickness $l$ is given by

$$
C=\frac{4 C_{0}}{\pi} \sum_{n=0}^{\infty} \frac{8}{2 n+1} \exp \left[\frac{-(2 n+1)^{2} \pi^{2} D t}{l^{2}}\right] \sin \frac{(2 n+1) \pi x}{l},
$$

where $C_{0}$ is initial concentration of potassium sorbate in film. 
The fractional release as a function of time is obtained by integrating Equation (2) over the thickness of the film [8]:

$$
\frac{M_{t}}{M_{\infty}}=1-\sum_{n=0}^{\infty} \frac{8}{(2 n+1)^{2} \pi^{2}} \exp \left[\frac{-(2 n+1)^{2} \pi^{2} D t}{l^{2}}\right],
$$

Equation (3) was used to simulate the theoretical diffusion curve.

For early stages $\left(M_{t} / M_{\infty}<2 / 3\right)$ of diffusion processes, the diffusivity of this work was calculated with the following Equation (4):

$$
D=\left(\frac{k l}{4}\right)^{2} \pi
$$

where $k$ is the slope of the linear regression of $M_{t} / M_{\infty}$ versus $t^{1 / 2}$.

The mechanism related to diffusion behavior for a plane sheet (flat film) system was investigated using the following equation [13] [14]:

$$
\frac{M_{t}}{M_{\infty}}=k \times t^{n},
$$

where $M_{t} / M_{\infty}$ is the fractional release of the potassium sorbate, $t$ is the release time, $k$ is a constant that depends on the macromolecular network characteristics of the film in addition to its interaction with the solution, and $n$ is the diffusion exponent characteristic of the release mechanism.

Fickian diffusion is characterized by $n=0.5$ which means diffusion is controlled by the diffusion coefficient (Case I system). A value of $n=1$ shows Case II and diffusion is very rapid compared with the relaxation process of polymer. Non-Fickian or anomalous diffusion is denoted by $0.5<n<1$. Values of $n>1$ indicate Super Case II transport [12].

\subsection{Swelling Measurements}

Swelling was determined as follows. Antibacterial gelatin samples (diameter $3 \mathrm{~mm}$ ) were dried at reduced pressure for 1 day, and weighed $\left(W_{d r y}\right)$. The films were swollen in $\mathrm{pH} 3.5,5.0$ and 6.8 for a certain time at $25^{\circ} \mathrm{C}$, blotted with a tissue, and weighed again $\left(W_{s}\right)$. Experiments were carried out in triplicate. The swelling $(S)$ was calculated as:

$$
S=W_{s} / W_{d r y} .
$$

\section{Results and Discussion}

\subsection{Determination of Diffusion Coefficient}

Figure 1 shows fractional mass release from diffusion tests at $\mathrm{pH} 6.8$ under various potassium sorbate concentration. All release curves were similar in shape, although diffusion rates varied with potassium sorbate concentration. The detected amount of potassium sorbate migrated into the diffusion solution consistently increased with time. The diffusion coefficients $(D)$ calculated in this study with the early stage method (Equation (4)) are summarized in Table 1, which are in the order of $10^{-12} \mathrm{~m}^{2} / \mathrm{s}$. Table 1 shows that with increase of the potassium sorbate concentration, the diffusion coefficient of potassium sorbate increases. The transfer kinetics of diffusing potassium sorbate molecules depends greatly on the structure of the matrix. The addition of potassium sorbate increased the hydrophilic of gelatin film, the more concentration of potassium sorbate, the more hydrophilic. The hydrophilic of the matrix promotes potassium sorbate to migrate into water. Hence, an increase in potassium sorbate concentration results in higher diffusion coefficients of potassium sorbate.

Figure 2 shows the mechanism of different concentration of potassium sorbate diffusion in gelatin film. The $n$ values calculated from Figure 2 in this study with Equation (5) are summarized in Table 1. The estimated $n$ values are in the range from 0.43 to 0.52 and demonstrate that Fickian diffusion is the predominant mechanism of this release.

\subsection{Temperature Dependence of Diffusivity}

Diffusion coefficients of $0.5 \%$ potassium sorbate in gelatin films at different temperatures are shown in Table 2 . 


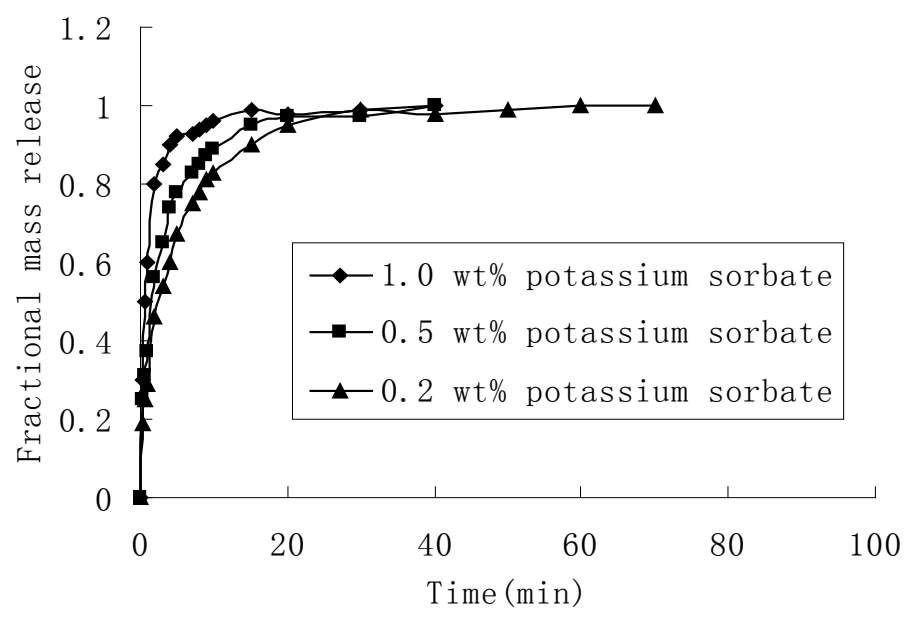

Figure 1. Time variation of potassium sorbate release from gelatin films at various potassium sorbate concentrations.

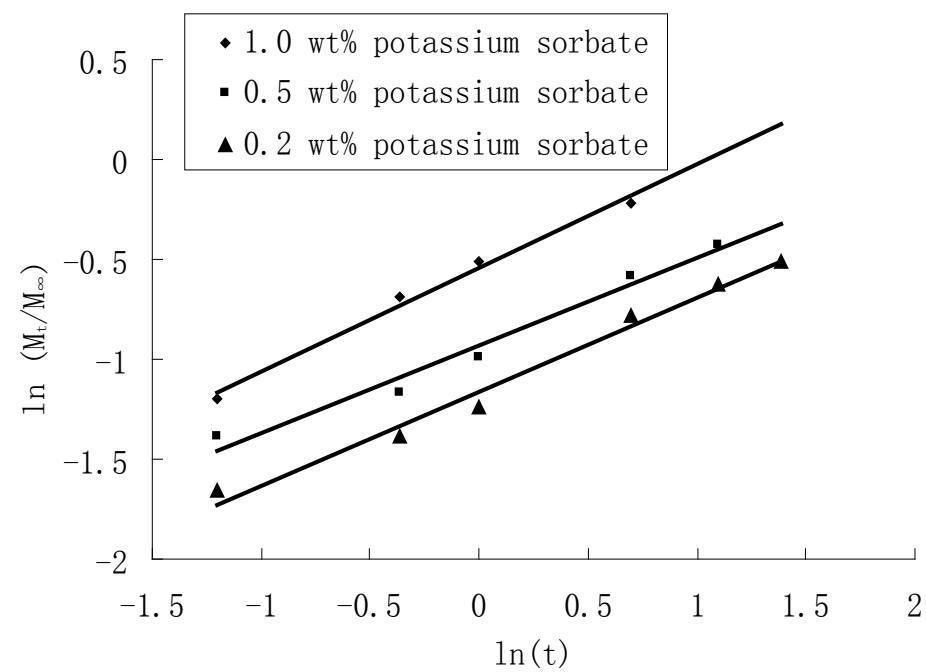

Figure 2. The mechanism of different concentration of potassium sorbate diffusion in gelatin film.

Table 1. Potassium sorbate diffusion coefficients in gelatin films.

\begin{tabular}{cccc}
\hline Potassium sorbate concentration (wt\%) & Film thickness (mm) & $D\left(\times 10^{-12} \mathrm{~m}^{2} / \mathrm{s}\right)$ & $n$ \\
\hline 0.2 & $0.072 \pm 0.003$ & 1.96 & 0.471 \\
0.5 & $0.065 \pm 0.001$ & 2.87 & 0.440 \\
1.0 & $0.068 \pm 0.001$ & 6.20 & 0.520 \\
\hline
\end{tabular}

Table 2. Diffusion coefficient of potassium sorbate in gelatin films at different temperatures.

\begin{tabular}{cc}
\hline Temperature $\left({ }^{\circ} \mathrm{C}\right)$ & $D\left(\times 10^{-12} \mathrm{~m}^{2} / \mathrm{s}\right)$ \\
\hline 5 & 1.36 \\
25 & 2.87 \\
35 & 5.21 \\
\hline
\end{tabular}


It can be seen that diffusivity coefficient increases with the temperature. When the temperature was raised from $5^{\circ} \mathrm{C}$ to $35^{\circ} \mathrm{C}$, diffusion coefficient increased about 4 times for potassium sorbate in gelatin film.

Activation energy $E_{a}$ can be calculated from the Arrhenius activation energy model,

$$
D=D_{0} \exp \left(-\frac{E_{a}}{R T}\right),
$$

where $D$ is the diffusion coefficient, $D_{0}$ is a constant, $E_{a}$ is activation energy for the diffusion process $(\mathrm{J} / \mathrm{mol}), \mathrm{R}$ is universal gas constant ( $\mathrm{J} / \mathrm{mol} \mathrm{K})$, and $T$ is absolute temperature $(\mathrm{K})$.

The Arrhenius plots is derived from logarithmic transform of Equation (6) and shown in Figure 3, which indicates significant effect of temperature on diffusion with the high correlation coefficient values $\left(r^{2}>0.95\right) . E_{a}$ is $31.05 \mathrm{~kJ} / \mathrm{mol}$ calculated from the plot.

\subsection{The Swelling Rate of Film at Different pH Values}

Figure 4 is swelling behavior of $0.5 \%$ potassium sorbate gelatin film in different receiving solution $\mathrm{pH}$ values. It can be seen that the film has obvious swelling behavior, and swells slowly after the initial stage of quick swelling, finally achieves swelling balance. The film has the higher swelling rate in $\mathrm{pH} 3.5$ than in $\mathrm{pH} 5.0$ and $\mathrm{pH}$ 6.8. The receiving solution $\mathrm{pH}$ value has effect on swelling rate of antibacterial gelatin film, this may be explained that the amino group in the network structure of membrane is protonated in the low $\mathrm{pH}$, leading to the increase of electrostatic repulsion and hydrophilicity, therefore the membrane structure becomes loose, and the swelling rate goes up.

\subsection{Receiving Solution pH Values Effect on Diffusivity}

Table 3 is pH effect on diffusion coefficient of $0.5 \%$ potassium sorbate in gelatin films. It can be seen that the diffusion coefficients of potassium sorbate increase with the decrease of $\mathrm{pH}$. Receiving solution $\mathrm{pH}$ values has certain effect on the diffusion process, which is associated with the swelling of the membrane. As shown in Figure 4, the higher the swelling rate of membrane, the larger the channel of membrane, which cause the high mobility of potassium sorbate in $\mathrm{pH}$ 3.5.

\section{Conclusion}

The fractional release of potassium sorbate from film increased proportionally with time up to the maximum and then plateaued, showing the diffusion coefficient in the order of $10^{-12} \mathrm{~m}^{2} / \mathrm{s}$. The results show possibility of antimicrobial food packaging by applying incorporation of potassium sorbate into gelatin based film. Estimated nvales showed that the diffusion mechanism of potassium sorbate followed Fick's law. It can be recognized from the release pattern of potassium sorbate that the amount of migrated potassium sorbate from gelatin based film satisfies its requirement for activity as preservative in foods. For the temperature dependence, a decrease in

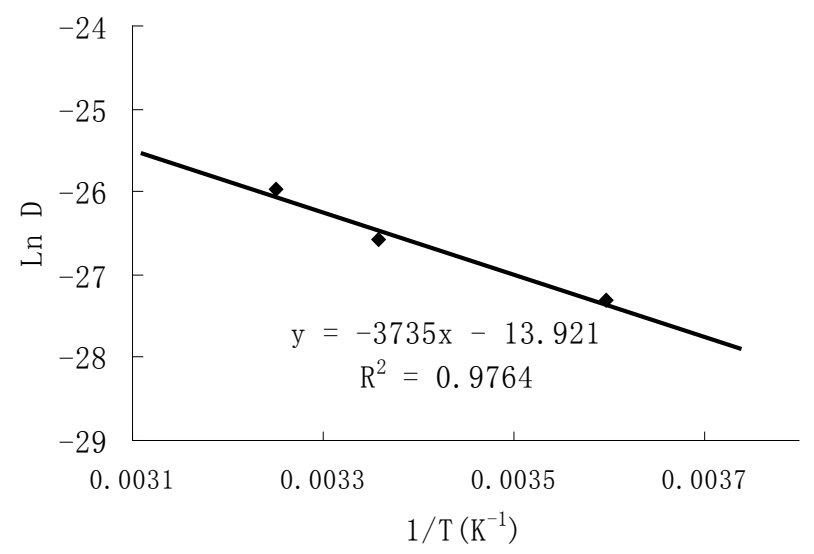

Figure 3. Temperature dependence of potassium sorbate diffusivity in gelatin film. 


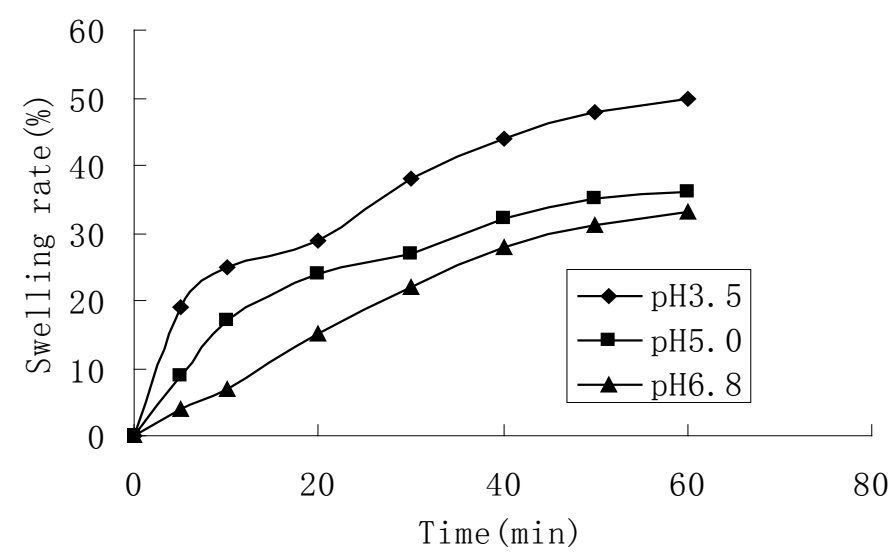

Figure 4. Swelling behavior of antibacterial gelatin film at different receiving solution $\mathrm{pH}$ values.

Table 3. pH effect on diffusion coefficient of potassium sorbate in gelatin films.

\begin{tabular}{cc}
\hline $\mathrm{pH}$ & $D\left(\times 10^{-12} \mathrm{~m}^{2} / \mathrm{s}\right)$ \\
\hline 3.5 & 3.26 \\
5.0 & 2.87 \\
6.8 & 2.27 \\
\hline
\end{tabular}

temperature from $35^{\circ} \mathrm{C}$ to $5^{\circ} \mathrm{C}$ resulted in a reduction of diffusion coefficients from $5.20 \times 10^{-12}$ to $1.36 \times 10^{-12}$ $\mathrm{m}^{2} / \mathrm{s}$. The diffusion coefficient of potassium sorbate is influenced by receiving solution $\mathrm{pH}$ values.

\section{Acknowledgements}

We acknowledge the financial support by the National Natural Science Foundation of China (Grant No. 51363018); Hainan Tropical Ocean University, Youth Scientific Research Fund Project (Grant No. QYQN201517).

\section{References}

[1] Suppakul, P., Miltz, J., Sonneveld, K., et al. (2003) Active Packaging Technologies with an Emphasis on Antimicrobial Packaging and Its Applications. Journal Food Science, 68, 408- 420. http://dx.doi.org/10.1111/j.1365-2621.2003.tb05687.x

[2] Bile, J., Bolzinger, M.A., Valour, J.P., et al. (2015) Antimicrobial Films Containing Microparticles for the Enhancement of Long-Term Sustained Release. Drug Development and Industrial Pharmacy, 1-7.

[3] Rodríguez-Martínez, A.V., Sendón, R., Abad, M.J., et al. (2016) Migration Kinetics of Sorbic Acid from Polylactic Acid and Seaweed Based Films into Food Simulants. LWT_Food Science and Technology, 65, 630-636. http://dx.doi.org/10.1016/j.lwt.2015.08.029

[4] Wang, H., Zhang, R., Zhang, H., et al. (2015) Kinetics and Functional Effectiveness of Nisin Loaded Antimicrobial Packaging Film Based on Chitosan/Poly (vinyl alcohol). Carbohydrate polymers, 127, 64-71. http://dx.doi.org/10.1016/j.carbpol.2015.03.058

[5] Vieira, M.G.A., da Silva, M.A., dos Santos, L.O., et al. (2011) Natural-Based Plasticizers and Biopolymer Films: A Review. European Polymer Journal, 47, 254-263. http://dx.doi.org/10.1016/j.eurpolymj.2010.12.011

[6] Ahmad, M., Benjakul, S., Prodpran, T., et al. (2012) Physico-Mechanical and Antimicrobial Properties of Gelatin Film from the Skin of Unicorn Leatherjacket Incorporated with Essential Oils. Food Hydrocolloids, 28, 189-199. http://dx.doi.org/10.1016/j.foodhyd.2011.12.003

[7] Choi, J.H., Choi, W.Y., Cha, D.S., et al. (2005) Diffusivity of Potassium Sorbate in א-Carrageenan Based Antimicrobial Film. LWT-Food Science and Technology, 38, 417-423. http://dx.doi.org/10.1016/j.lwt.2004.07.004 
[8] López, O.V., Giannuzzi, L., Zaritzky, N.E., et al. (2013) Potassium Sorbate Controlled Release from Corn Starch Films. Materials Science and Engineering: C, 33, 1583-1591. http://dx.doi.org/10.1016/j.msec.2012.12.064

[9] Türe, H., Gällstedt, M. and Hedenqvist, M.S. (2012) Antimicrobial compression-Moulded Wheat Gluten Films Containing Potassium Sorbate. Food Research International, 45, 109-115. http://dx.doi.org/10.1016/j.foodres.2011.10.012

[10] Moditsi, M., Lazaridou, A., Moschakis, T., et al. (2014) Modifying the Physical Properties of Dairy Protein Films for Controlled Release of Antifungal Agents. Food Hydrocolloids, 39, 195-203. http://dx.doi.org/10.1016/j.foodhyd.2014.01.011

[11] Ozdemir, M. and Floros, J.D. (2001) Analysis and Modeling of Potassium Sorbate Diffusion through Edible Whey Protein Films. Journal ofFood Engineering, 47, 149-155. http://dx.doi.org/10.1016/s0260-8774(00)00113-8

[12] Crank, J. (1975) The Mathematics of Diffusion. 2nd Edition. Clarendon Press, Oxford.

[13] Peppas, N.A. (1985) Analysis of Fickian and Non Fickian Drug Release from Polymers. Pharmaceutical Acta Helvetiae, 60, 110-111.

[14] Yoshida, C.M.P., Bastos, C.E.N. and Franco, T.T. (2010) Modeling of potassium Sorbate Diffusion through Chitosan Films. Food Science and Technology, 43, 584-589. http://dx.doi.org/10.1016/j.lwt.2009.10.005

Submit or recommend next manuscript to SCIRP and we will provide best service for you:

Accepting pre-submission inquiries through Email, Facebook, LinkedIn, Twitter, etc.

A wide selection of journals (inclusive of 9 subjects, more than 200 journals)

Providing 24-hour high-quality service

User-friendly online submission system

Fair and swift peer-review system

Efficient typesetting and proofreading procedure

Display of the result of downloads and visits, as well as the number of cited articles

Maximum dissemination of your research work

Submit your manuscript at: http://papersubmission.scirp.org/ 